\title{
Weaker Bonds with Shorter Bond Lengths
}

\section{Elfi Kraka \& Dieter Cremer}

Um dos paradigmas da química prevê que uma ligação mais curta de um dado tipo é sempre a ligação mais forte. Apesar disto funcionar qualitativamente para alguns compostos, não existe em geral prova de que isso seja sempre correto. Neste trabalho, nós discutimos moleculas para as quais ligações longas levam a ligações fortes ao contrário de ligações fracas. Isto é possível introduzindo constantes de força dos modos locais de estiramento como descritores de força de ligação confiáveis. Para as aminas fluoradas $\mathrm{NH}_{2} \mathrm{~F}(\mathbf{1}), \mathrm{NHF}_{2}(\mathbf{2})$, e $\mathrm{NF}_{3}$ (3), o comprimento de ligação NF diminui enquanto que a força da ligação diminui. Efeitos similares são encontrados para ligações envolvendo um elemento pesado com um efeito relativístico distinto. Uma razão para estes resultados será dada.

Palavras-chave: constantes de força modos locais, relação entre comprimento de ligação/força de ligação, fluoraminas.

One of the paradigms of chemistry predicts that the shorter the bond of a given type is always the stronger bond. Although this qualitatively holds for many compounds, there exists no general proof that this is always correct. Here, we discuss molecules, for which longer bonds lead to stronger rather than weaker bonds. This is possible by introducing the local mode stretching force constants as reliable bond strength descriptors. For the fluoroamines $\mathrm{NH}_{2} \mathrm{~F}(\mathbf{1}), \mathrm{NHF}_{2}(\mathbf{2})$, and $\mathrm{NF}_{3}(\mathbf{3})$, the NF bond length decreases whereas the NF bond strength decreases. Similar effects are found for bonds involving a heavy element with a distinct relativistic effect. A rational for these findings will be given.

Keywords: local mode force constants, bond length-bond strength relationship, fluoroamines. 


\section{Introduction}

Chemists measure the strength of a chemical bond with the help of the bond dissociation energy (BDE), which is the reaction energy of the dissociation of a molecule into two fragments. The BDE values are in general not reliable bond strength descriptors because they depend on both the bond strength and the stabilization of the fragments. For example, if ethane is split into two methyl radicals, the latter change their structure from pyramidal to planar structure, which is accompanied by rehybridization and a reorganization of the density distribution in the fragments. ${ }^{1}$ Since BDE values are positive (measuring the energy of an endothermic process), relaxation of the fragment geometry and reorganization of the charge distribution will stabilize the fragments and lower the BDE values thus suggesting a smaller strength for the bond being broken than it is in reality. ${ }^{1}$

Relativistic effects can also contribute to the stabilization of the fragments and reduce the bond strength. If in a closed shell molecule a bond involving one or two heavy atoms is broken, heavy atom radicals are generated that can be stabilized by a spin orbit coupling (SOC) effect. ${ }^{2}$ SOC occurs for a fractional occupation of $\mathrm{p}, \mathrm{d}$, or f-type orbitals. If the molecule being fragmented has a closed-shell ground state, SOC does not play a significant role. The fragments, however can benefit from strong first order SOC effects if their groundstate is degenerated as in the case of the halogen atoms or the $\mathrm{EH}$ radicals $(\mathrm{E}=\mathrm{O}, \mathrm{S}, \mathrm{Se} . \mathrm{Te})$. In this case, the stabilization of the fragments increases with the fourth power of the atomic number Z. ${ }^{3}$ This means that for Y-I or Y-TeH bonds, the BDEs are reduced by $6-8 \mathrm{kcal} / \mathrm{mol}$ as is shown by the data of Table 1 .

For non-degenerate ground states of a fragment produced in a dissociation reaction the SOC effect is of second order. The stabilization of the fragment due to SOC is irreversibly proportional to the excitation energy $\mathrm{T}_{\mathrm{e}}$ between ground and first excited state. Since this energy becomes smaller with increasing $\mathrm{Z}$ whereas it increases for increasing hydrogenation, stabilization of the fragments increases with $\mathrm{Z}$, however less for a $\mathrm{PbH}_{3}$ radical $(2.1 \mathrm{kcal} /$ mol, Table 1) than for a $\mathrm{BiH}_{2}$ radical $(4.4 \mathrm{kcal} / \mathrm{mol})$. In any case, the $\mathrm{BDE}$ values for the corresponding bonds are reduced and do no longer reflect the bond strength.
Table 1. Stabilization of H-XHn BDE values by spin orbit coupling (SOC) effects in $\mathrm{kcal} / \mathrm{mol}$ for a large variation of X.a

\begin{tabular}{|c|c|c|}
\hline Atom/Molecule & State & SOC \\
\hline $\mathbf{H}$ & $\left({ }^{2} \mathrm{~S}\right)$ & 0 \\
\hline $\mathbf{F}$ & $\left({ }^{2} \mathrm{P}\right)$ & -0.289 \\
\hline Cl & $\left({ }^{2} \mathrm{P}\right)$ & -0.841 \\
\hline $\mathrm{Br}$ & $\left({ }^{2} \mathrm{P}\right)$ & -3.457 \\
\hline I & $\left({ }^{2} \mathrm{P}\right)$ & -7.923 \\
\hline $\mathrm{OH}$ & $\left({ }^{2} \Pi\right)$ & -0.192 \\
\hline SH & $\left({ }^{2} \Pi\right)$ & -0.497 \\
\hline $\mathrm{SeH}$ & $\left({ }^{2} \Pi\right)$ & -2.479 \\
\hline TeH & $\left({ }^{2} \Pi\right)$ & -6.070 \\
\hline $\mathrm{NH}_{2}$ & $\left({ }^{2} A_{1}\right)$ & 0 \\
\hline $\mathrm{PH}_{2}$ & $\left({ }^{2} \mathrm{~A}_{1}\right)$ & 0 \\
\hline $\mathrm{AsH}_{2}$ & $\left({ }^{2} \mathrm{~A}_{1}\right)$ & -0.040 \\
\hline $\mathrm{SbH}_{2}$ & $\left({ }^{2} A_{1}\right)$ & -0.266 \\
\hline $\mathrm{BiH}_{2}$ & $\left({ }^{2} \mathrm{~A}_{1}\right)$ & -4.414 \\
\hline $\mathrm{CH}_{3}$ & $\left({ }^{2} A_{2}{ }^{\prime \prime}\right)$ & 0 \\
\hline $\mathrm{SiH}_{3}$ & $\left({ }^{2} \mathrm{~A}_{1}\right)$ & 0 \\
\hline $\mathrm{GeH}_{3}$ & $\left({ }^{2} \mathrm{~A}_{1}\right)$ & -0.003 \\
\hline $\mathrm{SnH}_{3}$ & $\left({ }^{2} \mathrm{~A}_{1}\right)$ & -0.089 \\
\hline $\mathrm{PbH}_{3}$ & $\left({ }^{2} \mathrm{~A}_{1}\right)$ & -2.101 \\
\hline
\end{tabular}

a) SOC energies calculated with the CASSCF state interaction approach using a Breit-Pauli operator. For calculational details, see Ref. 3

The BDE is a dynamic measure for the bond dissociation reaction, which, as long as the fragment stabilization energies are not known, cannot be used as an accurate bond strength descriptor. ${ }^{1}$ Therefore, it is desirable to use a dynamic measure of the bond strength being based on infinitesimally small bond distortions, which do not change the electronic structure of the molecule and, accordingly, do not require the determination of reorganization effects and fragment stabilization energies. Vibrational spectroscopy offers such a measure via the bond stretching frequencies and the corresponding force constants. The latter are the perfect descriptors for the bond strength because, contrary to the mass-depending frequencies, they are directly related to the electronic structure of a bond. However, the vibrational normal modes of a molecule are 
generally delocalized because of mode-mode coupling effects or Fermi resonances between vibrational modes and overtones. Therefore, a vibrational normal mode cannot be exclusively assigned to an individual bond or a particular structural unit. A solution to this problem will be presented in the next section.

\section{Results and Discussions}

Cremer and co-workers have recently demonstrated that for each molecule both a set of normal vibrational modes and a unique set of local vibrational modes exists. ${ }^{4}$ The force constants of the local bond stretching modes reliably describe the strength of the bonds of a molecule. ${ }^{5}$ Hence they can be used to investigate one of the paradigm of chemistry which predicts that the shorter bond of a given type is always the stronger bond. This has been found to be fulfilled in many cases on qualitative grounds, ${ }^{6}$ however there exists no theoretical proof of the paradigm, which has to do with the elusiveness of the chemical bond and the resulting difficulty of defining the bond strength.

In the following, we will demonstrate that it is not generally true that the shorter bond is the stronger bond. For this purpose, we consider the strength of the $\mathrm{NF}$ bond in the series $\mathrm{NH}_{2} \mathrm{~F}(\mathbf{1}), \mathrm{NHF}_{2}(2)$, and $\mathrm{NF}_{3}$ (3). Since these molecules are closely related, one can assume that, according to the above paradigm, the NF bond becomes stronger with decreasing NF bond length. However, as shown in Figure 1, the calculated local mode NF stretching force constants suggest the opposite: the shorter NF bonds are the weaker. They also suggest that the $\mathrm{NH}$ bonds behave normal in the series $\mathrm{NH}_{3}(4)$, 1, 2 (Figure 1). Since these results are obtained with very reliable quantum chemical methods $\left(\operatorname{CCSD}(\mathrm{T})^{7} / \mathrm{cc}\right.$-aug$\mathrm{pVTZ}^{8}$ for both geometry and local mode frequencies, COLOGNE12 quantum chemistry package ${ }^{9}$ ), there is no doubt about the reliability of the results. Hence, they have to be rationalized in the following.

The bond length can be considered as being close to the sum of covalent radii of the atoms connected by the bond. The covalent radius decreases with increasing oxidation state of an atom, which is easy to determine for transition metal cations but more difficult for the atoms of the second period. In the series $\mathbf{1 - 3}$, the strong withdrawal of negative charge by first one, then two, and finally three $\mathrm{F}$ atoms leads an increase of the positive charge at the $\mathrm{N}$ atom (1: -288 me; $2:+186$ me; $\mathbf{3}:+636$ me, see Figure 1) by almost 1 charge unit, which converts the $\mathrm{N}$ atom effectively into a $\mathrm{N}$ cation with a smaller covalent radius. Hence, the shorter bond length is just a result of the different electron structure of the $\mathrm{N}$ atom, which has lost almost 1e. The bond shortening in turn causes an increase in pair repulsion between the electron lone pairs at the $\mathrm{F}$ and the $\mathrm{N}$ atom. Despite the bond shortening, destabilizing 4-electron interactions reduce the bond strength. The NF local mode force constants decrease with decreasing NF bond length and reflect the weakening of the NF bonds (Figure 1). Similar effects can be always expected when strongly electronegative substituents effectively reduce the covalent radius of a central atom and this effect is accompanied by increasing bond destabilization.

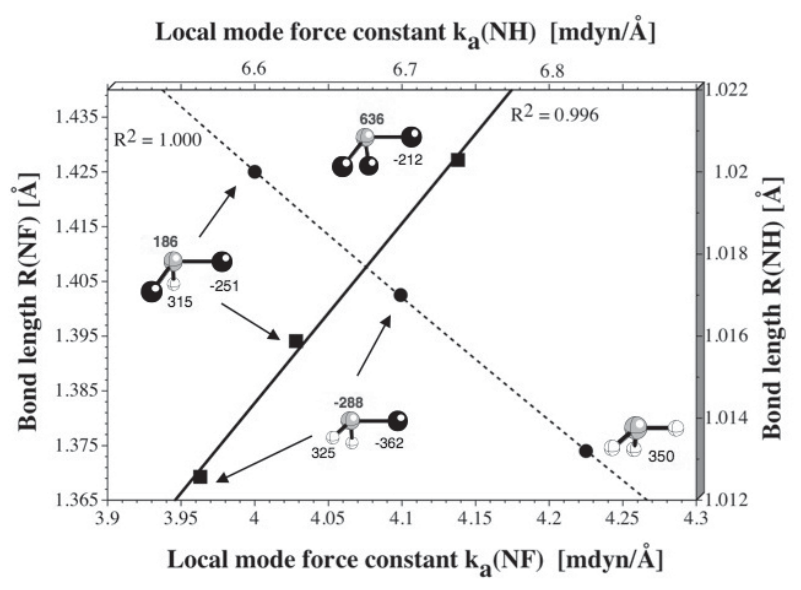

Figure 1. Local mode stretching force constants of $\mathrm{NF}$ and $\mathrm{NH}$ bonds in $\mathrm{NH}_{2} \mathrm{~F}(\mathbf{1}), \mathrm{NHF}_{2}(\mathbf{2}), \mathrm{NF}_{3}(3)$, and $\mathrm{NH}_{3}(\mathbf{4})$ in dependence of the equilibrium bond lengths $\mathrm{R}(\mathrm{NF})$ and $\mathrm{R}(\mathrm{NH})$ calculated at the $\mathrm{CCSD}(\mathrm{T}) /$ aug-cc-pVTZ level of theory. ${ }^{7,8}$ (NF: bold line; $\mathrm{NH}$ : dashed line). $\mathrm{NBO}^{12}$ charges are given in me.

In the case of the NH bonds, there is no lone pair repulsion between the $\mathrm{N}$ and $\mathrm{H}$ atoms. Therefore, the $\mathrm{N}-\mathrm{H}$ bonds of $\mathbf{4}$ compared with those of $\mathbf{1}$ and $\mathbf{2}$ follow the paradigm that shorter bonds are stronger bonds (see Figure 1).

Another electronic effect, which can lead to an inversion of the commonly expected bond length-bond strength relationship is the relativistic mass-velocity 
effect, which is found for heavy and super-heavy atoms. ${ }^{10,11}$ For atoms such as $\mathrm{Au}$ or $\mathrm{Hg}$, the mass-velocity effect leads to a $6 \mathrm{~s}$ orbital contraction thus effectively reducing the covalent radius of the $\mathrm{Hg}$ and leading to shorter Hg-Y bonds. However, the 6s-orbital contraction makes the 6s-electrons less available for bonding, i.e. the donor activity of $\mathrm{Hg}$ is reduced thus leading to weaker bonds. ${ }^{10,11}$

In conclusion, we have shown in this work that a) local mode stretching force constants are a sensitive tool for monitoring the strength of a chemical bond; b) the paradigm of chemistry which expects the shorter bond of a given type always to be the stronger bond is not true in general as discussed for fluorinated amines 1-3; and c) both BDE and bond length are not reliable measures for the bond strength.

\section{Acknowledgements}

This work was financially supported by the National Science Foundation, Grant CHE 1152357. We thank SMU for providing computational resources.

\section{References}

1. Cremer, D.; Kraka, E. From Molecular Vibrations to Bonding, Chemical Reactions, and Reaction Mechanism. Curr. Org. Chem., 2010, 14, 1524 .

2. See for example, Marian, C.M. Spin-Orbit Coupling in Molecules in Reviews in Computational Chemistry, Vol. 17, Lipkowitz, K.B. Edt., Wiley, New York, 2001, chapter 3, 99.

3. Kraka, E.; Zou, W.; Freindorf, M.; Cremer, D. Energetics and Mechanism of the Hydrogenation of, XHn for Group IV to Group VII Elements X, J. Chem. Theor. Comp. in press.

4. Zou, W.; Kalescky, R.; Kraka, E.; Cremer, D. Relating Normal Vibrational Modes to Local Vibrational Modes with the help of an
Adiabatic Connection Scheme. J. Chem. Phys., in press.

5. Kraka, E.; Larsson, J.A.; Cremer, D. Generalization of the Badger Rule Based on the Use of Adiabatic Vibrational Modes in Vibrational Modes in Computational IR Spectroscopy, Grunenberg, J. Edt., Wiley, New York, 2010, p. 105.

6. Pauling, L. Nature of the Chemical Bond, 3rd ed. Cornell University Press: Ithaca, New York, 1960.

7. Pople, J.A.; Raghavachari, K; Trucks, G.W.; Pople, J.A.; HeadGordon, M. A fifth-order perturbation comparison of electron correlation theories. Chem. Phys. Lett., 1989, 157, 479.

8. Dunning Jr., T. Gaussian basis sets for use in correlated molecular calculations. I. The atoms boron through neon and hydrogen $J$. Chem. Phys. 1989, 90, 1007

9. Kraka, E.; Filatov, M.; Zou, W.; Gräfenstein, J.; Izotov, D.; Gauss, J.; He, Y.; Wu, A.; Polo, V.; Olsson, L.; Konkoli, Z.; He, Z.; Cremer, D. COLOGNE12. 2012.

10. Cremer, D.; Kraka, E.; Filatov, M. Bonding in mercury molecules described by the normalized elimination of the small component and coupled cluster theory. ChemPhysChem, 2008, 9, 2510.

11. Kaka, E.; Filatov, M.; Cremer, D. Comparison of gold bonding with mercury bonding. Croat. Chim. Acta, 2009, 82, 233; in honor of Prof. Z. Maksic.

12. Weinhold, F.; Landis, C. R. Valency and Bonding: A Natural Bond Orbital Donor-Acceptor Perspective; Cambridge U. Press, 2003.

\section{Elfi Kraka* \& Dieter Cremer}

CATCO Group, Department of Chemistry, Southern Methodist University, 3215 Daniel Ave, Dallas, Texas, 75275-03114, USA.

*e-mail: ekraka@smu.edu 